\title{
Development of a web-based information system for monitoring of hemodialysis adequacy
}

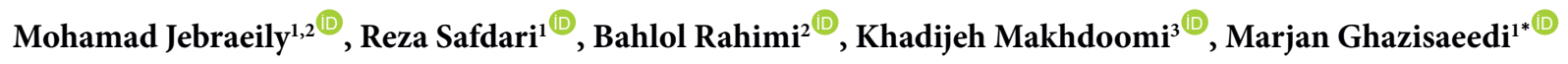 \\ ${ }^{1}$ Department of Health Information Management, School of Allied Medical Sciences, Tehran. University of Medical Sciences, Tehran, Iran \\ ${ }^{2}$ Department of Health Information Technology, School of Allied Medical Sciences, Urmia University of Medical Sciences, Urmia, Iran \\ ${ }^{3}$ Nephrology and Renal Transplant Research Center, Urmia University of Medical Sciences, Urmia, Iran
}

\section{A R T I C L E I N F O \\ Article Type: \\ Original \\ Article History: \\ Received: 12 October 2018 \\ Accepted: 23 January 2019 \\ ePublished: 28 February 2019}

\section{Keywords:}

Information system

Hemodialysis adequacy

End-stage renal disease

\begin{abstract}
A B S T R A C T
Introduction: Given the significant impact of dialysis adequacy on the quality of life and survival of hemodialysis patients, an information system for assessment of the treatment plan is necessary.

Objectives: In this study, a web-based information system was developed to monitor hemodialysis adequacy in hemodialysis center of Taleghani hospital of Urmia.

Patients and Methods: The study is organized into four phases; determination of minimum data set, designing an information system for monitoring the dialysis adequacy, implementing in a hospital setting and finally impact of the information system on dialysis adequacy.

Results: This system designed in ASP.NET platform and C\# programming language and SQL, server database was applied for managing the data. This system implemented in server of hemodialysis center of the hospital. The results of statistical analysis showed that information system on the hemodialysis adequacy indicators has a significant effect $(P<0.05)$.

Conclusion: We found that the designed information system is capable of promoting hemodialysis adequacy.
\end{abstract}

Implication for health policy/practice/research/medical education:

The designed information system can determine dialysis time, based on the NKF-K/DOQI guidelines and evaluate the effectiveness of treatment based on the hemodialysis adequacy indicators. This information system helps the nephrology specialists in the timely identification of patients with inadequacy status by creating the necessary alerts and reminders.

Please cite this paper as: Jebraeily M, Safdari R, Rahimi B, Makhdoomi K, Ghazisaeedi M. Development of a web-based information system for monitoring of hemodialysis adequacy. J Nephropharmacol. 2019;8(2):e19. DOI: 10.15171/npj.2019.19.

Introduction

Today, the incidence of chronic diseases is constantly growing causing death in more than $60 \%$ of cases around the world (1). One of the chronic diseases is end-stage renal disease (ESRD) which more than 80 thousand people annually lose their lives through it $(2,3)$. Indeed, ESRD is the final stage of kidney failure that is marked by the complete or nearly complete irreversible loss of renal function (4). However, renal replacement therapies lead to prolonging the life of millions of patients with ESRD among which hemodialysis is the most common therapy that over two million people all over the world survive through this procedure $(5,6)$.

Despite the progress of the quality of care services and the advance in hemodialysis machines, the rate of disability and mortality in hemodialysis patients are unexpectedly high (7). The hemodialysis process should have provided the adequacy to improve their quality of life and rate of survival (6-8). To accomplish this, nephrologists are to allocate the optimal dose of hemodialysis properly according to the characteristics and specific situations of each patient. It is important to do the process of hemodialysis based on clinical guidelines. Moreover, they are required to continue to monitor dialysis adequacy so that if necessary, modifications are made in the treatment plan (8-10).

As reported by the NKF-K/DOQI (National Kidney Foundation- Kidney Disease Outcomes Quality Initiative) guidelines, a urea reduction ratio (URR) over $65 \%$ and a $\mathrm{Kt} / \mathrm{V}$ over 1.4 are proposed to hemodialysis adequacy (11).

In Iran, more than 28 thousand people are treated with hemodialysis. Researches indicate that in more than $56 \%$ 
of the patients, $\mathrm{Kt} / \mathrm{V}$ is less than $1.2(12-14)$. Given the significant impact of dialysis adequacy on the quality of life and survival of hemodialysis patients, it is essential that there is an information system for assessment of the treatment plan and continuous monitoring of the dialysis adequacy in the management of these patients (9-11). An information system can be used as a support tool to follow up the effectiveness of treatment as well as to evaluate the performance of hemodialysis centers (15).

The results of the studies have indicated that using information systems in dialysis centers improves the quality of services as well as the effectiveness of the care provided, which in turn reduces medical errors, costs and time of dialysis, and gives the providers of dialysis services the possibility of focusing on the status of their patients more effectively $(9,10,15,16)$.

Renal Epidemiology and Information Network in France gives valuable information to health care providers through recording the data related to the dialysis process and dialysis adequacy so that, by focusing on the results of treatment, they improved the decision-making process and the quality of care along with following the clinical guidelines in the process of dialysis (17).

\section{Objectives}

In this study, a web-based information system was developed to monitor hemodialysis adequacy in a hemodialysis center and its impact on the dialysis adequacy indicators was evaluated.

\section{Patients and Methods}

\section{Study population}

The study was organized into four phases:

\section{Determination of minimum data set}

At this stage, a researcher-made questionnaire was designed according to the latest version of the clinical guideline NKF-K/DOQI (2015) in the field of dialysis adequacy and using the specialized forms of hemodialysis. A group of 30 experts (including 15 nephrologists, 10 dialysis nurses and 5 health information managers) were asked to rate the degree of value of data elements by using a five-point Likert scale (1; low important to 5; very important) via Delphi technique. The items identified as important or highly important by more than $50 \%$ of the experts, were entered in the ultimate list of minimum data set.

Designing an information system for monitoring the dialysis adequacy

A work group of experts including 4 nephrologists, 3 nurses and 2 health information management professionals in the hemodialysis ward of Taleghani hospital was assigned to draw conceptual and logical diagrams.

First, the tables of scenarios describing actors, objectives, and relevant events, preconditions of the process, the mainstream of events, post-conditions, and possible alternatives were developed.

Then, using Enterprise Architect software which is powerful software for analysis and designing unified modeling language diagrams, the graphs were drawn.

Implementing a web-based information system in the hemodialysis center

The system, designed in Visual Studio and C\# programming language in NET4.5, is used for high-level. To store data, SQL Server was used. The system was then installed on Taleghani hospital's server computer since the hospital possesses one of the largest hemodialysis centers in Iran. Prior to the implementation of the system, training was provided to the end users of the center. Then, test was run for a week's period to identify and correct system problems. After verification by users, the system was officially launched in May 2017. Information from the paper records of 375 hemodialysis patients (the total number of patients referred) was gradually fed to the system.

\section{Evaluation of impact of information system in the dialysis adequacy}

In the evaluation phase, we selected the pre-post implementation method. Before the implementation of the system in Taleghani dialysis center of Urmia, the hemodialysis adequacy indicators were collected from paper records of 375 patients. After nine months of implementation of the system, hemodialysis adequacy indicators were evaluated for the same patients.

\section{Ethical issues}

Human rights were respected in accordance with the Helsinki Declaration 1975, as revised in 1983. The study was approved by the ethics committee of Tehran University of Medical Sciences (Ethical cod\# IR.TUMS.REC.1394.673). The informed consent was taken from hemodialysis patients.

\section{Statistical analysis}

In the phase of determining of minimum data set, the items identified as important or highly important by more than $50 \%$ of the experts, were entered in the ultimate list of minimum data set. In order to evaluate the impact of information system on hemodialysis adequacy indicators, the mean of Kt/V, URR, eKt/V of the patients before and after the implementation of the information system were compared by using of SPSS 20 software and paired $t$ test.

Results

A total of 537 data elements in seven main classes including demographic information, medical history, treatment plan, dialysis sessions, lab tests, hemodialysis adequacy and reports were obtained.

The users were provided with a username, password 
combination to log in the system on their own according to the role-based access control.

In the treatment plan recorded by the nephrologists, the system calculated the volume of urea distribution $(\mathrm{V})$, clearance of the dialyzer $(\mathrm{K})$, and duration of dialysis $(\mathrm{T})$ based on the algorithms derived from the latest version clinical guideline NKF-K /DOQI (11). The physician determines the type of access to vascular, ultrasound, and heparin dose in the treatment plan and can record medical comments, drug prescriptions, diets, and trainings for the patients (Figure 1).

The data required to calculate dialysis adequacy are automatically obtained from dialysis sessions and the results of blood urea nitrogen test before and after the dialysis are recorded and then the system calculates the indices.

After the statuses of the indices of adequacy are calculated, they are displayed in the following colors including (green; dialysis adequacy, yellow; alert for adequacy, and red; dialysis inadequacy). After calculating the adequacy indices, if the indices are less than the standard, warnings will be sent to the nephrologists via SMS (Figure 2).

The latest version of clinical guideline NKF-K/DOQI was used to identify the value of the indicators (11).

In the reporting section of the system, the user can view the information about the adequacy indicators in the form of tables and graphs based on history and observe the process of changes in any time period (Figure 3 ).

The results of statistical analysis showed that the implementation of the information system on the hemodialysis adequacy indicators has a significant positive effect and it definitely improves the efficiency of monitoring the adequacy $(P<0.05$; Table 1$)$.

\section{Discussion}

Web-based information system to monitor dialysis adequacy proposes the optimal dose of hemodialysis based on the unique characteristics of each patient. Moreover, in cases where the values of the calculated indices are less than the standard, the system alerts nephrologists through short messaging system.

In South Korea, Ku et al made an application on iPhone operation system with the iPad. The common data elements were determined based on a content list in three sections (demographic data of the patient, dialysis data, and outcome data) using Xcode programming language. Meanwhile, they used ASTM standards for information exchange (18).

Soetomo et al developed a knowledge-based information system in health care hemodialysis in collaboration with physicians and nurses to assess the parameters of dialysis patients with an analytical performance, including hemodialysis adequacy, transparency of small molecules, hemodialysis output, transparency of intermediate molecules, general blood pressure control and nutritional status (9).

Shima and Yasuda designed and implemented a webbased information management system for dialysis patients. A total of 964 data elements in three categories including the primary information of the patient, information related to dialysis treatment, and information

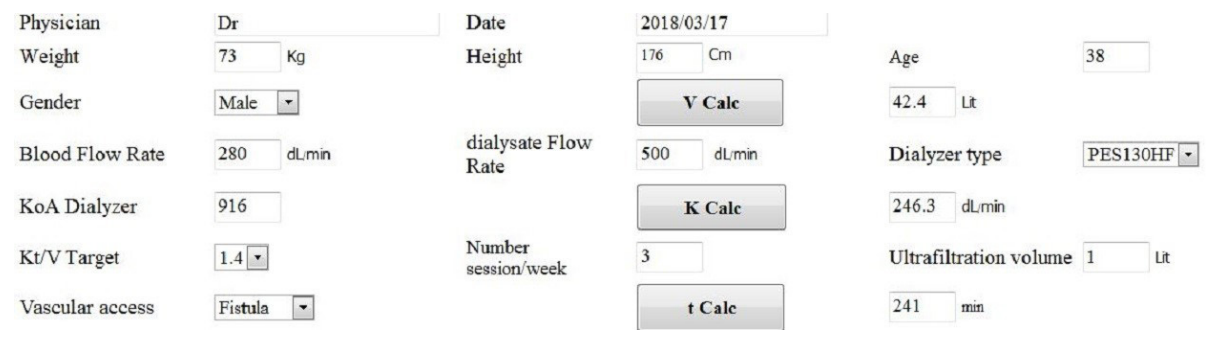

Figure 1. Treatment plan of system.

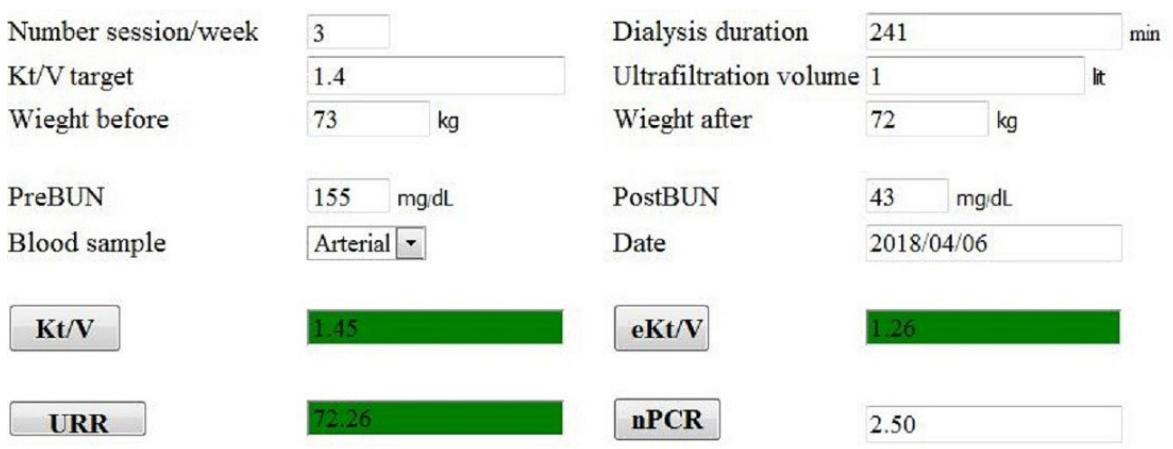

Figure 2. Calculation of dialysis adequacy. 


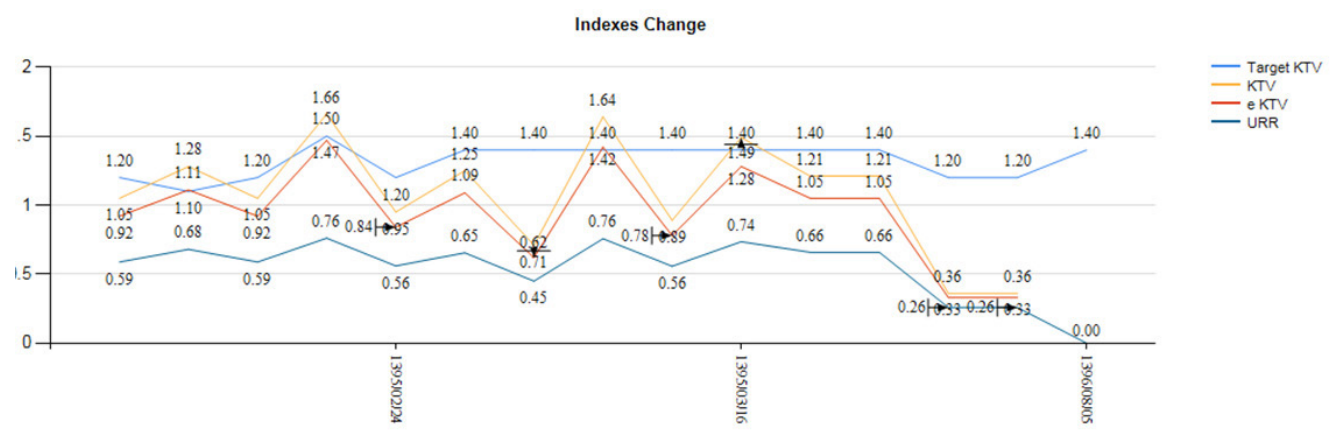

Figure 3. Reports of dialysis adequacy indicators.

related to the transmission of the patient chosen for the system. In order to manage the database, relational database management system database, DB2, was used. In addition, HTML format was used for the network environment (19).

Cheng in Malaysia developed dialysis data management system by using PHP programming language and the MySQL database to store the data (20).

In China, Xie et al designed national kidney data system in a portal structure which is implemented based on a Java web application and uses Apache server services. They also used MySQL database to manage the data (21).

Yao et al implemented an intelligent management system of hemodialysis as a client-server system and used $\mathrm{C}++$ programming language and MySQL database (22).

In our research, we developed a web-based information system in ASP.NET platform and C\# programming language and implemented SQL Server databases for handling data.

\section{Conclusion}

We have found that the hereby designed information system is capable of promoting hemodialysis adequacy through timely identification of patients with inadequacy status by creating the necessary alerts and reminders. This information system helps the healthcare providers to access patient information with no effort at any desired time and place without the need for any special software. It also enables physicians to prescribe dialysis time based on the specific parameters of every patient. To improve the support and care hemodialysis patients receive, it is necessary that the information system should be created in all the dialysis centers with the purpose of evaluating centers' performance based on the hemodialysis adequacy

Table 1. Comparison of hemodialysis adequacy indicators pre-post implementation

\begin{tabular}{lccc}
\hline $\begin{array}{c}\text { Adequacy } \\
\text { indicators }\end{array}$ & $\begin{array}{c}\text { Pre- } \\
\text { implementation }\end{array}$ & Post-implementation & P value \\
\hline Kt/V & 1.23 & 1.47 & 0.003 \\
eKt/V & 1.02 & 1.25 & 0.001 \\
URR & 66.27 & 71.48 & 0.003 \\
\hline
\end{tabular}

indicators and efficiency of resources.

Limitations of the study

This information system developed in a single hemodialysis center study with a limited number of patients.

\section{Acknowledgments}

I sincerely appreciate all healthcare providers in hemodialysis center of Taleghani hospital of Urmia city that cordially contributed to this study.

\section{Authors' contribution}

MJ, MGh, RS, BR and KhM designed the study, observed accuracy and validity of the study. MJ and KhM collected the data and follow the study. MJ and MGh wrote the paper. RS, BR and KhM edited the final manuscript.

\section{Conflicts of interest}

The authors declared no competing interests.

Ethical considerations

Ethical issues (including plagiarism, data fabrication, double publication) have been completely observed by the authors.

\section{Funding/Support}

This paper is derived from $\mathrm{PhD}$ thesis of health information management (No. 90-2145-8002) (by Mohamad Jebraeily), financially funded by Tehran University of Medical Sciences.

\section{References}

1. Murtagh FE, Addington-Hall J, Higginson IJ. The prevalence of symptoms in end-stage renal disease: a systematic review. Adv Chronic Kidney Dis. 2007;14:82-99. doi: $\quad$ 10.1053/j.ackd.2006.10.001.

2. Fauci AS. Harrison's Principles of Internal Medicine. New York: McGraw-Hill Medical; 2008.

3. Chauveau P, Nguyen H, Combe C, Chêne G, Azar R, Cano $\mathrm{N}$, et al. Dialyzer membrane permeability and survival in hemodialysis patients. Am J Kidney Dis. 200;45:565-71. doi:10.1053/j.ajkd.2004.11.014

4. Tayyebi A, Babahaji M, Ebadi A, Eynollahi B. Study of 
the effect of Hatha Yoga exercises on stress, anxiety and depression among hemodialysis patients. J Crit Care Nurs. 2011;4:67-72.

5. Jebraeily M, Safdari R, Rahimi B, Makhdoomi K, Ghazisaeidi M. The application of intelligent information systems in hemodialysis adequacy promotion. J Renal Inj Prev. 2018;7(2):64-68. doi: 10.15171/jrip.2018.16

6. Flythe JE, Curhan GC, Brunelli SM. Shorter length dialysis sessions are associated with increased mortality, independent of body weight. Kidney Int 2013;83:104-13. doi: $\quad 10.1038 / \mathrm{ki} .2012 .346$.

7. Gotch F. The basic, quantifiable parameter of dialysis prescription is $\mathrm{Kt} / \mathrm{V}$ urea; treatment time is determined by the ultrafiltration requirement; all three parameters are of equal importance. Blood Purif 2007;25(1):18-26. doi:10.1159/000096392.

8. Puñal J, Lema LV, Sanhez-Guisande D, Ruano-Ravina A. Clinical effectiveness and quality of life of conventional haemodialysis versus short daily haemodialysis: a systematic review. Nephrol Dial Transplant 2008;23(8):2634-46. doi: 10.1093/ndt/gfn010.

9. Soetomo RD. A Knowledge-based Hemodialysis HealthCare Information System with Analytical Functions of Temporal Assessments for Monitoring and Treatment Plan of Hemodialysis Patient. Industrial Electronics Seminar (IES); 2012; Surabaya, Indonesia.

10. Rodriguez RA, Hotchkiss JR, O'Hare AM. Geographic information systems and chronic kidney disease: racial disparities, rural residence and forecasting. J Nephrol. 2013;26(1):3-15. doi: 10.5301/jn.5000225

11. Foundation NK. KDOQI clinical practice guideline for hemodialysis adequacy: 2015 update. Am J Kidney Dis. 2015;66:884-930. doi: 10.1053/j.ajkd.2015.07.015.

12. Hojjat M. Hemodialysis adequacy in patients with chronic renal failure. J Crit Care Nurs. 2009;2:61-6.
13. Mahdavi-Mazdeh M, Zamyadi M, Nafar M. Assessment of management and treatment responses in haemodialysis patients from Tehran province, Iran. Nephrol Dial Transplant 2008;23:288-93. doi: 10.1093/ndt/gfm580.

14. Aghighi M, Heidary Rouchi A, Zamyadi M, MahdaviMazdeh M, Rajolani H, Ahrabi S. Dialysis in Iran. Iran J Kidney Dis 2008;2:11-5.

15. Javed F, Savkin AV, Chan GS, Mackie JD, Lovell NH. Recent advances in the monitoring and control of haemodynamic variables during haemodialysis: a review. Physiol Meas 2012;33:R1-R31. doi: 10.1088/0967-3334/33/1/R1.

16. Yu B, Wijesekera D. Building Dialysis Workflows into EMRs. Procedia Technology. 2013;9:985-95.

17. Couchoud C, Stengel B, Landais P, Aldigier JC, De Cornelissen F, Dabot C, et al. The renal epidemiology and information network (REIN): a new registry for endstage renal disease in France. Nephrol Dial Transplant. 2006;21:411-8. doi: 10.1093/ndt/gfi198.

18. Ku HS, Kim S, Kim H, Chung HJ, Park YR, Kim JH. DialysisNet: Application for Integrating and Management Data Sources of Hemodialysis Information by Continuity of Care Record. Healthc Inform Res. 2014;20(2):145-51. doi: 10.4258/hir.2014.20.2.145.

19. Shima Y, Takashi Y. The Comprehensive Management System of Dialysis Patients: Creation and Application of the Database. St Marianna Med J. 2007;35:23-30.

20. Cheng HL. Centralised data for dialysis patients [dissertation]. UTAR; 2013.

21. Xie F, Zhang D, Wu J, Zhang Y, Yang Q, Sun X, et al. Design and implementation of the first nationwide, web-based Chinese Renal Data System (CNRDS). BMC Med Inform Decis Mak. 2012;12:11. doi: 10.1186/1472-6947-12-11

22. Yao ZM, Bai LJ, Guo FS. Design and Implementation of Hemodialysis Intelligent Management System. Applied Mechanics and Materials 2012;121:1804-8.

Copyright $\odot 2019$ The Author(s); Published by Society of Diabetic Nephropathy Prevention. This is an open-access article distributed under the terms of the Creative Commons Attribution License (http://creativecommons.org/licenses/by/4.0), which permits unrestricted use, distribution, and reproduction in any medium, provided the original work is properly cited. 